\title{
Problemas geopolíticos y sociales en AmÉrica Latina
}

Desde finales del siglo pasado se asiste a la reconfiguración y multiplicación de instancias de concertación, cooperación e integración; sin embargo, en la actualidad existen una serie de cuestionamientos y reclamos de índole social de diversa naturaleza.

Dichas demandas marcan la necesidad de establecer una agenda vinculada a materias que van desde una mayor equidad en la distribución del ingreso hasta el reconocimiento de derechos personales como la igualdad de género y la violencia hacia la mujer, generando replanteos en la gestión de los distintos niveles gubernamentales.

Los planteamientos en muchos casos ponen en juego la gobernabilidad democrática, tal los casos Chile -que había resultado un modelo ejemplificador en materia de organización y crecimiento económico-, Ecuador, Colombia y Bolivia, que sufrieron verdaderas revueltas populares haciendo tambalear en algunos casos a la cúpula gobernante y, en otro -la crisis boliviana-, terminando por socavar la institucionalidad vigente para instalar un nuevo gobierno de transición. Tampoco escapa de este contexto la situación de Venezuela con una crisis humanitaria, socioeconómica y política sin precedentes.

Resulta innegable que los posicionamientos de América Latina a nivel regional e internacional, desde la primera parte del Siglo XXI, obligan a examinar no sólo las condiciones de infraestructura, producción y distribución de las economías, sino también la incorporación y reconocimiento de nuevos derechos que han desarrollado reacciones en todo el mundo y no pueden resultar ajenos en cuanto a su tratamiento en los ámbitos de cooperación e integración latinoamericanos.

El contexto descripto ha sido receptado por los estudios que conforman este nuevo número de "Aportes para la Integración Latinoamericana".

En tal sentido, en la Sección Tema Central se publica el trabajo realizado por el Dr. Álvaro Álvarez de la Universidad Nacional del Centro de la Provincia de Buenos Aires (UNCPBA) titulado: Integración e infraestructura en América del Sur. Aportes para el estudio del rol estratégico de la Hidrovía Paraguay-Paraná en la integración regional. En el mismo se destaca el papel preponderante del desarrollo de planes de infraestructura a nivel regional que posibiliten un crecimiento de las relaciones de 
intercambio entre los distintos Estados. El artículo resalta la importancia de la Hidrovía Paraguay-Paraná como un corredor central de los circuitos espaciales de producción de la región y del comercio a nivel internacional.

En la Sección Estudios se incluye el trabajo denominado Violencia de Género contra las mujeres en América Latina: una reflexión crítica en torno a las agendas de género en la integración regional. Los casos de MERCOSUR y SICA, cuya coautoría pertenece a las maestrandas Fabiana Rivas Monje y Malena Zunino Folle de la Universidad de Buenos Aires (UBA). En el mismo se destaca la incipiente incorporación del tema vinculado a la violencia de género en la agenda de la integración latinoamericana entendiendo que, si bien los procesos de integración en la región datan de mediados del siglo $X X$, no se ha incorporado de manera regular la temática de la violencia contra la mujer como parte de la agenda a nivel de los esquemas de integración. Se analizan puntualmente los casos del MERCOSUR y del SICA como testigos de una problemática creciente a nivel mundial.

El trabajo incorporado a la Sección Opinión titulado EI MERCOSUR en la estrategia de poder global brasileña (2003-2010) de la Mag. Celeste Box de la Universidad Nacional de La Plata (UNLP) y de la Universidad de Buenos Aires, efectúa un análisis de la acumulación de poder mostrada por Brasil durante el periodo de gobierno de Luiz Inacio Lula Da Silva y, a partir de ello, se explica cómo dicha concentración generó una tendencia de acentuada hegemonía en la región en general y en el MERCOSUR en particular.

Asimismo, los Documentos que integran este número son los que se detallan a continuación:

\section{- COMUNIDAD ANDINA DE NACIONES -CAN-}

Declaración Presidencial de Lima. 50 años de la Comunidad Andina de Naciones. Lima, Perú, 26 de mayo de 2019.

\section{- ALIANZA DEL PACIFICO}

XIV Cumbre de la Alianza del Pacifico. Declaración de Lima, Perú, 6 de julio de 2019

\section{- ALIANZA DEL PACIFICO}


Declaración conjunta entre los Estados Parte del Acuerdo Marco de la Alianza del Pacifico y la Organización para la Cooperación y el Desarrollo Económico. Lima, Perú, 5 de julio de 2019.

\section{- SICA}

LIII Reunión Ordinaria de Jefes de Estado y de Gobierno de los Países Miembros del Sistema de Integración Centroamericana (SICA). Ciudad de Guatemala, Guatemala, 5 de junio de 2019.

\section{- CARICOM}

Conferencia de Jefes de Gobierno en la $40^{\circ}$ Reunión de Santa Lucía aprobando la Declaración de St. Johns, 3 al 5 de julio de 2019.

\section{- MERCOSUR}

Comunicado conjunto de los Presidentes de los Estados Partes del MERCOSUR y Estados Asociados, en ocasión de la LIV Cumbre de Presidentes. República Argentina, Ciudad de Santa Fe, 17 de julio de 2019. 